http://dx.doi.org/10.32929/2446-8355.2020v29n1p61-75

\title{
DESEMPENHO DA CULTIVAR DE FEIJÃO-CAUPI BRS NOVAERA SOB NÍVEIS DE IRRIGAÇÃO E ADUBAÇÃO EM AMBIENTE PROTEGIDO
}

\author{
Douglas Gonçalves Guimarães ${ }^{1 *}$, Leandro Menezes Oliveira ${ }^{1}$, Murilo Oliveira Guedes ${ }^{2}$, \\ Gabriel Fernandes Pinto Ferreira ${ }^{1}$, Thiago Reis Prado ${ }^{1}$, Cláudio Lúcio Fernandes Amaral ${ }^{3}$
}

${ }^{1}$ Doutorando, Programa de Pós-graduação em Agronomia, Universidade Estadual do Sudoeste da Bahia, Vitória da Conquista - BA. *E-mail do autor para correspondência: douglasgg@ hotmail.com.

${ }^{2}$ Graduando do curso de Agronomia da Universidade Estadual do Sudoeste da Bahia, Vitória da Conquista - BA. ${ }^{3}$ Docente, Departamento de Ciências Biológicas, Universidade Estadual do Sudoeste da Bahia, campus de Jequié - BA.

Recebido: 06/06/2019; Aceito: 21/03/2020

RESUMO: A deficiência hídrica e a falta de adubação são fatores limitantes na produção de feijão-caupi, especialmente no Nordeste Brasileiro, onde a maioria dos cultivos são de subsistência realizados pela agricultura familiar. O objetivo deste trabalho foi avaliar o desempenho da cultivar de feijão-caupi 'BRS Novaera' cultivada em vasos submetida a diferentes níveis de irrigação e adubação em ambiente protegido. O experimento foi conduzido em blocos casualizados, com três repetições no esquema fatorial 4 x 2, com quatro níveis de irrigação $(40 \%, 60 \%, 80 \%$ e $100 \%$ de irrigação para capacidade de vaso) e dois níveis de adubação (com e sem uso de adubos a base de nitrogênio $(\mathrm{N})$, fósforo $(\mathrm{P})$ e potássio $(\mathrm{K})$ ). Nas condições estudadas, observou-se que a maior produtividade de grãos foi obtida com $72 \%$ de irrigação para capacidade de vaso e que a adubação NPK resultou em incremento no número de vagens por planta de $105,5 \%$ e produtividade de grãos de $135,7 \%$.

Palavras-chaves: Vigna unguiculata (L.) Walp. Produtividade. Déficit hídrico. Fertilizante.

\section{PERFORMANCE OF BRS NOVAERA COWPEA CULTIVAR SUBMITTED TO DIFFERENT IRRIGATION AND FERTILIZATION STRATEGIES IN PROTECTED ENVIRONMENT}

\begin{abstract}
Water deficiency and lack of fertilization are limiting factors in the production of cowpea, especially in the Brazilian Northeast, where most of the crops are cultivated for subsistence farming. The objective of this work was to evaluate the performance of 'BRS Novaera' cowpea cultivated in pots, under different irrigation levels and fertilization in a protected environment. The experiment was conducted in a randomized block design with three replications in a 4 x 2 factorial, with four irrigation levels $(40 \%, 60 \%, 80 \%$ and $100 \%$ irrigation of pot capacity) and two fertilization levels (with and without nitrogen $(\mathrm{N})$, phosphorus (P) and potassium (K) fertilizers). Under the conditions studied, it was observed that the highest grain yield was obtained with $72 \%$ irrigation for pot capacity and that NPK fertilization resulted in $105.5 \%$ higher number of pods per plant and $135.7 \%$ higher grain yield.
\end{abstract}


Keywords: Vigna unguiculata (L.) Walp. Productivity. Water deficit. Fertilizer.

\section{INTRODUÇÃO}

O feijão-caupi (Vigna unguiculata (L.) Walp.), conhecido também por macassar ou feijão-de-corda é uma leguminosa granífera, pertencente à família Fabaceae (CRUZ et al., 2012). É uma cultura de muita relevância socioeconômica, em especial no Nordeste Brasileiro. Segundo Rivas et al. (2016), os grãos de feijão-caupi são uma importante fonte de proteína para as comunidades do semi-árido.

Segundo o Instituto Brasileiro de Geografia e Estatística (IBGE), a região Nordeste, que em sua maioria são compostos por agricultores familiares, no ano de 2017 apresentou produtividade média de apenas $310,3 \mathrm{~kg} \mathrm{ha}^{-1}$, muito inferior a região Centro-Oeste, em especial ao estado do Mato Grosso, que apresenta cultivos tecnificados, com irrigação e adubação e que apresentou uma produtividade média de 1.274,2 $\mathrm{kg} \mathrm{ha}^{-1}$ (IBGE, 2020).

O feijão-caupi é uma cultura cultivada em quase todo o Nordeste sob seca e, portanto, estando sujeito a escassez de água pela fraca distribuição de chuvas (BASTOS et al., 2011). A baixa produtividade nesta região é devida à reduzida disponibilidade de nutrientes no solo (RODRIGUES et al., 2012) e ao cultivo não tecnificado (MONTEIRO et al., 2012). Além disso, as restrições de áreas para cultivo tendem a se tornar mais severas com o efeito das mudanças climáticas (YADAV et al., 2015).

A magnitude da perda de produtividade de grãos de feijão-caupi deve-se à intensidade do déficit hídrico e do estádio do ciclo da planta em que ocorre esse déficit, assim, a irrigação é uma das principais alternativas para contornar esse problema, uma vez que permite suprir a quantidade de água para o adequado crescimento e desenvolvimento desta cultura (BASTOS et al., 2017).

A agricultura moderna é dependente da aplicação de insumos, em especial fertilizantes e pesticidas, face à disponibilidade de nutrientes considerados essenciais para esta espécie (DASTAGER et al., 2011). Segundo Martins et al. (2017), para o completo crescimento e adequado desenvolvimento das culturas, além da calagem, é necessária a correção da fertilidade do solo, com destaque para o nitrogênio $(\mathrm{N})$, fósforo $(\mathrm{P})$ e potássio $(\mathrm{K})$, que são macronutrientes requeridos em maiores quantidades. $\mathrm{O} \mathrm{N}$ é constituinte de macromoléculas importantes como os ácidos nucleicos (DNA e RNA), proteínas e clorofila, o P é muito importante para os processos energéticos, pois é componente do trifosfato de adenosina (ATP), entre outros, e o $\mathrm{K}$ embora não seja constituinte de macromoléculas celulares, é importante para os processos que envolvem o carregamento de fotoassimilados (MARTINS et al., 2017).

As cultivares de feijão-caupi possuem características genéticas, fisiológicas e morfológicas intrínsecas e, portanto, apresentam respostas diferentes às condições edafoclimáticas locais (SANTOS, 2013). A cultivar 'BRS Novaera' foi originada em cruzamentos realizados na Embrapa Meio-Norte em 2000 e embora seja uma cultivar muito adequada à agricultura empresarial, é também adequada à agricultura familiar (FREIRE FILHO et al., 2008). 
Pelo papel fundamental da água e de nutrientes essenciais na produção do feijão-caupi, objetivou-se com este estudo, avaliar o desempenho da cultivar de feijão-caupi 'BRS Novaera', cultivada em ambiente protegido sob níveis de irrigação com 40\%, 60\%, 80\% e $100 \%$ da capacidade de vaso e com ou sem o uso de adubação com fertilizantes a base de N, P e K.

\section{MATERIAL E MÉTODOS}

O experimento foi conduzido de maio a setembro de $2018 \mathrm{em}$ ambiente protegido, com polietileno no teto e nas laterais com tela sombrite 50\%, na área experimental da Universidade Estadual do Sudoeste da Bahia (UESB), campus de Vitória da Conquista - BA. Com latitude de $14^{\circ} 53^{`}$ Sul e longitude de $40^{\circ} 47^{`}$ Oeste, a região tem clima classificado como tropical de altitude (Cwb), segundo a classificação de Köppen. As respectivas temperaturas e umidades relativas máximas e mínimas no interior do ambiente protegido durante a condução do experimento são informadas na Figura 1.

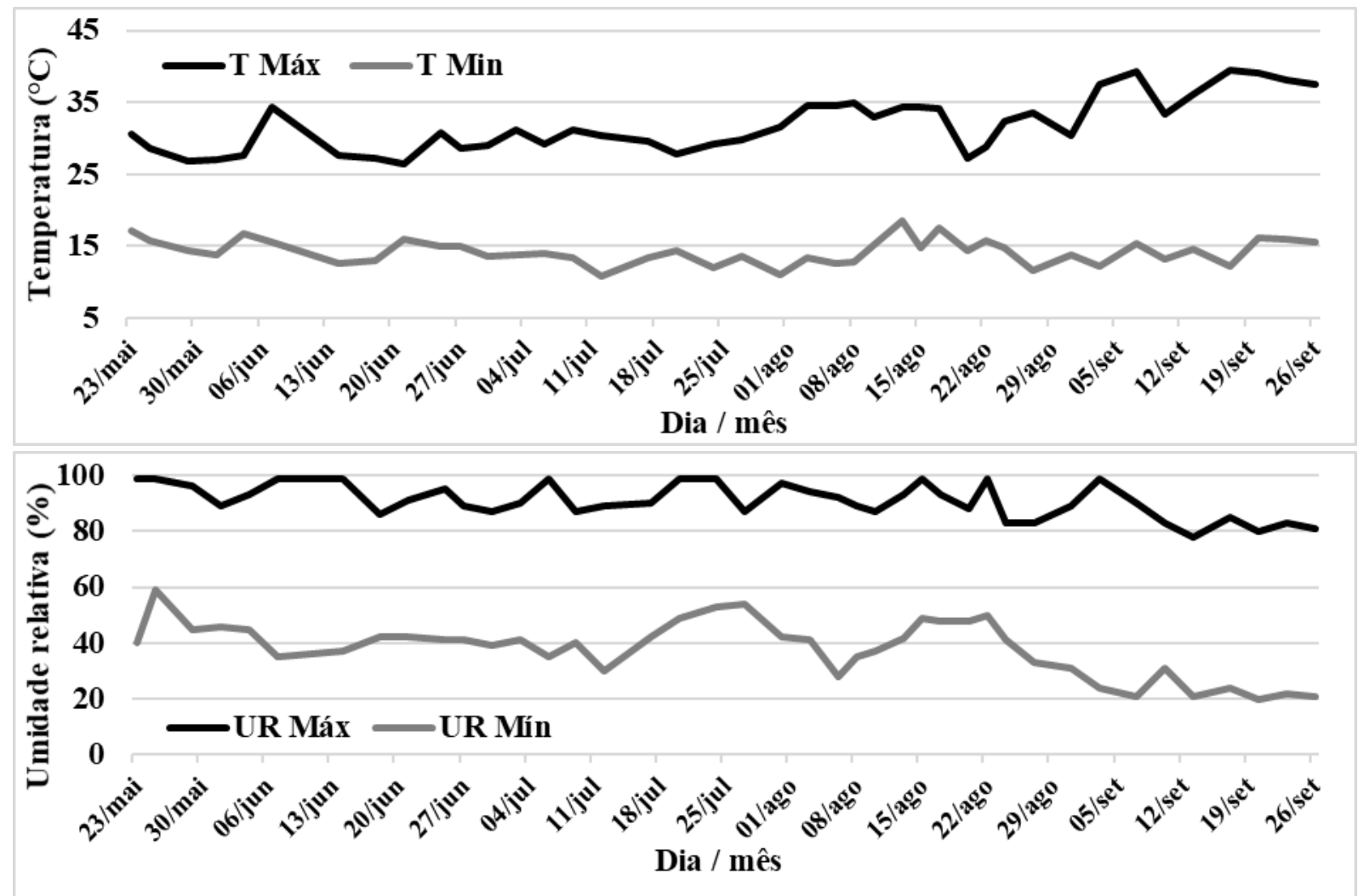

Figura 1. Temperaturas e umidades relativas máximas e mínimas no ambiente protegido durante o experimento. Maximum and minimum temperatures and relative humidity in the protected environment during the experiment.

Fonte: Autoria própria. Own authorship.

O solo utilizado para o experimento foi coletado na área experimental da UESB em uma camada 0-20 cm de profundidade, sua composição granulométrica foi de 59\% de areia grossa, $16 \%$ de areia fina, $3 \%$ de silte e $22 \%$ de argila, sendo sua classe textural classificada como franco argilo arenosa. A análise química de fertilidade do solo apresentou os seguintes resultados: $\mathrm{pH}$ em água: 5,0; $\mathrm{P}: 4,0 \mathrm{mg} \mathrm{dm}^{-3}$ (Extrator Mehlich-1); $\mathrm{K}^{+}:$0,18 $\mathrm{cmol}_{\mathrm{c}} \mathrm{dm}^{-3} ; \mathrm{Ca}^{2+}$ : 
1,2 $\mathrm{cmol}_{\mathrm{c}} \mathrm{dm}^{-3} ; \mathrm{Mg}^{2+}: 0,9 \mathrm{cmol}_{\mathrm{c}} \mathrm{dm}^{-3} ; \mathrm{Al}^{3+}: 0,2 \mathrm{cmol}_{\mathrm{c}} \mathrm{dm}^{-3} ; \mathrm{H}^{+}: 2,6 \mathrm{cmol}_{\mathrm{c}} \mathrm{dm}^{-3}$; Soma de Bases: $2,3 \mathrm{cmol}_{\mathrm{c}} \mathrm{dm}^{-3}$; CTC efetiva: $2,5 \mathrm{cmol}_{\mathrm{c}} \mathrm{dm}^{-3}$; CTC a pH 7,0:5,1 $\mathrm{cmol}_{\mathrm{c}} \mathrm{dm}^{-3}$; Saturação por bases: $45 \%$; Saturação por alumínio: $8 \%$ e matéria orgânica: $6,0 \mathrm{~g} \mathrm{dm}^{-3}$.

Foram utilizados como parcelas experimentais vasos de polietileno com quatro furos para escorrimento de água e preenchidos com 12,2 litros de solo em cada um. Cerca de sessenta dias antes da implantação do experimento foi realizada a calagem, com aplicação de proporcionalmente de $956 \mathrm{~kg} \mathrm{ha}^{-1}$ de calcário com intenção do valor de saturação de bases alcançar $60 \%$, conforme recomendado para a cultura.

Para o trabalho, foi utilizado a cultivar de feijão-caupi 'BRS Novaera', que apresenta hábito de crescimento indeterminado, porte semi-ereto, cor do tegumento branca e classe comercial branco (FREIRE FILHO et al., 2008). O experimento foi realizado sob esquema fatorial 4 x 2, com quatro níveis de irrigação $(40 \%, 60 \%, 80 \%$ e $100 \%$ de irrigação para capacidade de vaso) e dois níveis de adubação (com e sem NPK), em blocos casualizados com três repetições. Em cada vaso foram semeadas quatro sementes, com posterior desbaste, deixando duas plantas por vaso. O controle de plantas invasoras foi realizado manualmente sempre que necessário.

De acordo com Casaroli e Van Lier (2008), analogamente ao conceito de capacidade de campo, em estudos ou práticas agrícolas com plantas cultivadas em vasos utiliza-se frequentemente a "capacidade de vaso". Com isso, a quantidade de água para a irrigação utilizada no trabalho foi calculada pelo método de retenção de água do solo para chegar à capacidade de vaso, conforme metodologia de Casaroli e Van Lier (2008). Foram realizadas irrigações a cada dois dias e com auxílio de uma balança foi realizado a pesagem dos vasos para determinação da quantidade de água que deveria ser adicionada a fim dos vasos voltarem a seus determinados pesos pré-estabelecidos conforme cálculos para alcançarem 40\%, 60\%, $80 \%$ e $100 \%$ da capacidade de vaso, com cada vaso pesando $17,150 \mathrm{~kg}, 17,830 \mathrm{~kg}, 18,510 \mathrm{~kg}$ e $19,190 \mathrm{~kg}$, respectivamente.

Para o tratamento "com NPK", os vasos tiveram uma adubação de plantio com proporcionalmente: $80 \mathrm{~kg} \mathrm{ha}^{-1}$ de $\mathrm{P}_{2} \mathrm{O}_{5}$ na forma de superfosfato simples e $20 \mathrm{~kg} \mathrm{ha}^{-1} \mathrm{de}_{2} \mathrm{O}$ na forma de cloreto de potássio e após o desbaste (cerca de 15 dias após a emergência) foi realizado a adubação proporcional de $30 \mathrm{~kg} \mathrm{ha}^{-1}$ de $\mathrm{N}$, na forma de ureia, conforme recomendado para a cultura pela análise química do solo (MELO; CARDOSO, 2003). No tratamento "sem NPK" não foi realizado adubação.

No período final do estádio vegetativo, foram realizadas as avaliações de altura de plantas e diâmetro de caule e, utilizando duas folhas centrais, foi medido o índice de clorofila Falker (ICF) com medição das clorofilas $a, b$ e total, utilizando o clorofilômetro modelo CFL1030 (ClorofiLOG, Falker Automação Agrícola, Brasil).

Após a colheita foram realizadas as seguintes avaliações: Número de vagens por planta; massa de vagem; comprimento de vagem; número de grãos por vagem; índice de grãos; massa de 100 grãos e produtividade de grãos: Estimado a partir da produção de grãos de cada parcela, corrigido por $13 \%$ de umidade e transformado para $\mathrm{kg} \mathrm{ha}^{-1}$ considerando o estande recomendado para a cultura de 160 mil plantas por hectare. 
Após a obtenção dos dados, foram realizados os testes de normalidade e homogeneidade e em seguida a análise de variância e teste "F". Para as características que apresentaram diferença significativa para níveis de irrigação, foi realizado à análise de regressão e as características que apresentaram diferença para adubação foram submetidas ao teste Tukey a 5\% de probabilidade, com auxílio do programa estatístico SISVAR (FERREIRA, 2014).

\section{RESULTADOS E DISCUSSÕES}

No período final do estádio vegetativo da cultura, as variáveis analisadas foram a altura de plantas, diâmetro de caule e índice de clorofila Falker $a, b$ e total. Observa-se na Tabela 1 que as características altura e diâmetro apresentaram diferença significativa apenas para adubação e, os índices de clorofila Falker $a, b$ e total, demonstraram diferença significativa apenas para níveis de irrigações.

Tabela 1. Resumo da análise de variância e coeficientes de variação referentes às características altura de plantas (ALT), diâmetro de caule (DIÂ), índice de clorofila Falker $a$ (ICF $a$ ), índice de clorofila Falker $b$ (ICF $b$ ) e índice de clorofila Falker total (ICF T) da cultivar de feijão-caupi 'BRS Novaera' sob níveis de irrigação e com ou sem adubação. Summary of variance analysis and variation coefficients for plant height (ALT), stem diameter (DIÂ), Falker a chlorophyll index (ICF a), Falker b chlorophyll index (ICF b) and total Falker chlorophyll index (ICF T) of 'BRS Novaera' cowpea cultivar under irrigation levels and with or without fertilization.

\begin{tabular}{lcccccc}
\hline \multicolumn{1}{c}{ Fontes de } & & \multicolumn{5}{c}{ Quadrados médios } \\
\cline { 3 - 7 } \multicolumn{1}{c}{ variação } & GL & ALT & DIÂ & ICF $a$ & ICF $b$ & ICF T \\
\hline Blocos & 2 & 7,07 & $1,96^{*}$ & 12,78 & 11,54 & 45,06 \\
Irrigação (I) & 3 & 26,26 & 0,80 & $48,52^{*}$ & $75,09^{*}$ & $243,49^{*}$ \\
Adubação (A) & 1 & $793,50^{*}$ & $13,05^{*}$ & 41,74 & 31,86 & 146,52 \\
I x A & 3 & 22,39 & 0,56 & 5,31 & 27,31 & 51,43 \\
Resíduo & 14 & 17,78 & 0,32 & 11,36 & 14,33 & 48,63 \\
\hline C.V. (\%) & 2 & 13,37 & 10,5 & 10,09 & 27,67 & 14,81 \\
\hline
\end{tabular}

Nota: *Significativo pelo teste " $\mathrm{F}$ " a $5 \%$ de probabilidade. Note: *Significant by the " $F$ " test at $5 \%$ probability. Fonte: Autoria própria. Own authorship.

Considerando a característica altura de plantas, observa-se na Tabela 2, que as plantas que foram submetidas a adubação NPK apresentaram altura média de 37,29 cm e as plantas que não tiveram adição de NPK altura de $25,79 \mathrm{~cm}$. Assim, a falta de adubação NPK no presente estudo resultou em diminuição da altura das plantas em 31\%. Santiago et al. (2017) também observaram reduções da altura de plantas quando submetidas a deficiências de macronutrientes, sendo o nitrogênio o nutriente que mais afetou esta característica, com redução de $65 \%$ com sua deficiência.

Segundo Miranda et al. (2017), o N é o nutriente mais absorvido pelas plantas de feijãocaupi e tem o maior efeito no desenvolvimento das culturas. Este nutriente serve como constituinte de muitos componentes da célula vegetal, incluindo clorofila, aminoácidos e ácidos nucleicos, assim, a deficiência de $\mathrm{N}$ inibe rapidamente o crescimento vegetal (TAIZ et al., 2017). 
Tabela 2. Médias de altura de plantas e diâmetro de caule em plantas da cultivar de feijãocaupi 'BRS Novaera' sob níveis de irrigações e com ou sem adubação NPK. Mean plant height and stem diameter in plants of 'BRS Novaera' cowpea cultivars under irrigation levels and with or without NPK fertilization.

\begin{tabular}{lcc}
\hline Adubação & Altura $(\mathrm{cm})$ & Diâmetro $(\mathrm{mm})$ \\
\hline Com NPK & $37,29 \mathrm{a}$ & $6,12 \mathrm{a}$ \\
Sem NPK & $25,79 \mathrm{~b}$ & $4,64 \mathrm{~b}$ \\
\hline
\end{tabular}

Nota: *Médias seguidas pela mesma letra na coluna não diferem entre si, pelo teste Tukey a 5\% de probabilidade. Note: *Means followed by the same letter in the column do not differ from each other, by the Tukey test at $5 \%$ probability.

Fonte: Autoria própria. Own authorship.

O diâmetro de caule foi afetado pela adubação, as plantas com NPK apresentaram média de diâmetro de $6,12 \mathrm{~mm}$ e as que não foram adubadas apresentaram média de 4,64 mm, uma redução de $24,2 \%$ na falta dos três elementos. Santiago et al. (2018), igualmente constataram redução do diâmetro de caule na deficiência destes nutrientes, só que observados de maneira individual, as reduções dos diâmetros foram de $60,4 \%, 35,4 \%$ e $38 \%$ para N, P e $\mathrm{K}$, respectivamente.

A falta de adubação destes macronutrientes resultaram em reduções de características morfológicas das plantas, possivelmente, devido principalmente a falta de adubação com nitrogênio, que é um nutriente que requer uma demanda elevada e que forma macromoléculas de grande importantes nas plantas, como a clorofila, que é responsável pela captação da energia solar para que ocorra a fotossíntese (MARTINS et al., 2017).

A determinação dos teores de clorofila da folha é importante devido a atividade fotossintética da planta depender, em parte, da capacidade da folha em absorver luz (SALLA et al., 2007). Na Figura 2 são apresentadas as regressões dos índices de clorofila Falker $a$ (ICF $a), b$ (ICF $b$ ) e total (ICF T). Observa-se regressão linear, com tendência decrescente, para os três níveis, ou seja, com aumento da irrigação, ocorreu a diminuição dos respectivos ICF.

Observa-se na Figura 2, que o ICF $a$ apresentou uma diminuição proporcionalmente inferior ao ICF $b$ com o aumento da irrigação. O ICF $a$ regrediu apenas $18 \%$ entre os extremos (40\% a 100\% de irrigação para capacidade de vaso), por outro lado, a redução do ICF $b$ foi de $46 \%$, indicando que o ICF $b$ é mais sensível a mudanças com variação da irrigação. O abatimento dos valores de ICF T foi de $27 \%$ entre o maior e o menor valor estudado.

Os resultados indicaram que o déficit hídrico induziu as plantas a uma maior produção de clorofilas, entretanto, este comportamento contraria as observações de Bastos et al. (2011), que utilizando o mesmo clorofiLOG constataram redução de $16 \%$ no índice médio de clorofila nas plantas que foram submetidas ao déficit hídrico e de Oliveira et al. (2014), que avaliando feijão-fava concluíram que o estresse hídrico interferiu no estado nutricional da planta e diminuiu o ICF. 


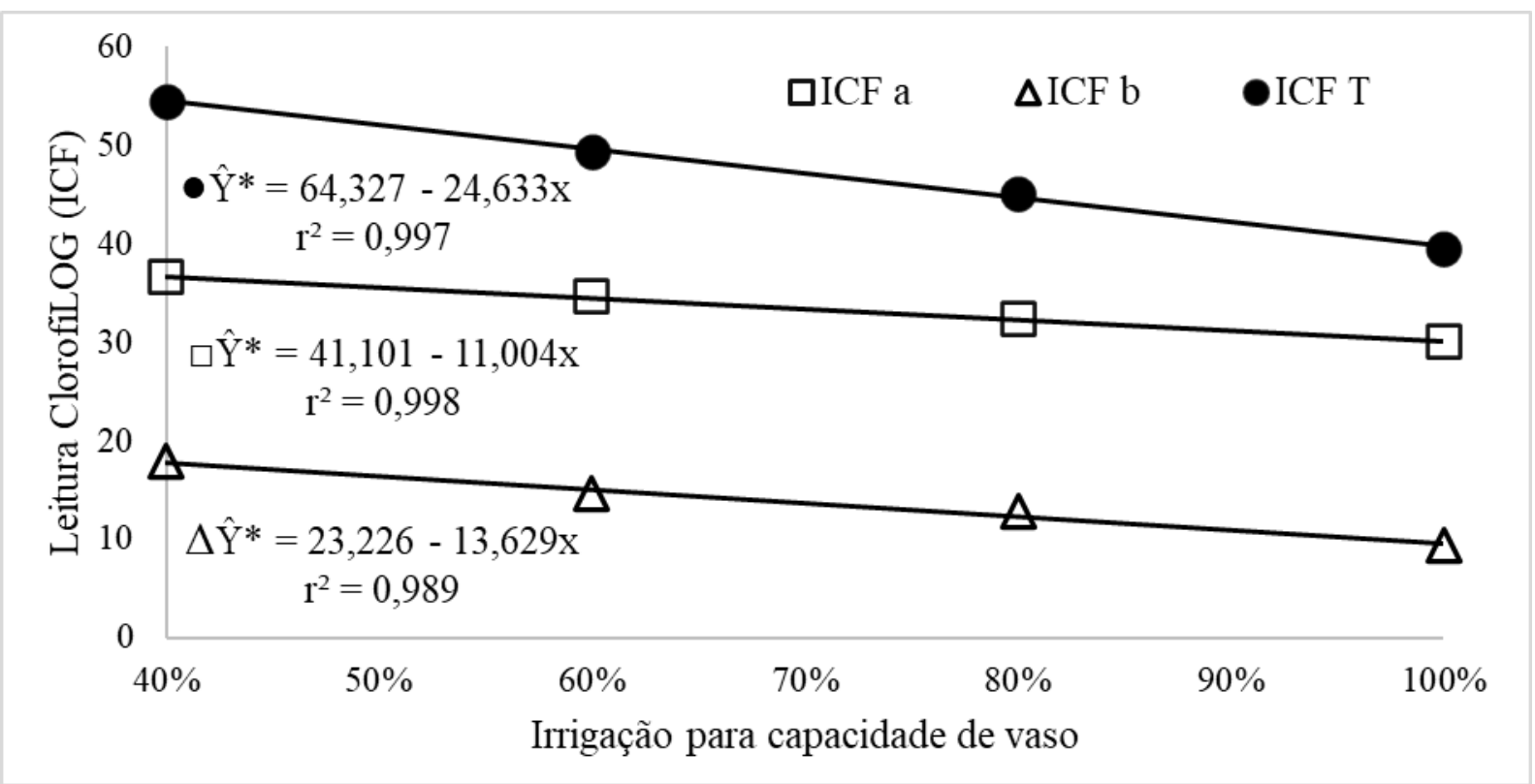

Nota: *Significativo, a 5\% de probabilidade, pela análise de variância da Regressão. Note: *Significant, at 5\% probability, by Regression analysis of variance.

Figura 2. Índice de Clorofila Falker $a$ (ICF $a$ ), Índice de Clorofila Falker $b$ (ICF $b$ ) e Índice de Clorofila Falker Total (ICF T) em plantas da cultivar de feijão-caupi 'BRS Novaera' submetidas a níveis de irrigação para capacidade de vaso. Falker a chlorophyll index (ICF a), Falker $b$ chlorophyll index (ICF b) and Total Falker chlorophyll index (ICF T) in 'BRS Novaera' cowpea plants submitted to irrigation levels for pot capacity.

Fonte: Autoria própria. Own authorship.

Tabela 3. Resumo da análise de variância e coeficientes de variação referentes às características produtividade de grãos (PROD), número de vagens por planta (NVP) e massa de 100 grãos (M100G) em plantas da cultivar de feijão-caupi 'BRS Novaera' sob níveis de irrigações e com ou sem adubação. Summary of analysis of variance and coefficients of variation regarding grain yield (PROD), number of pods per plant (NVP) and mass of 100 grains (P100G) in 'BRS Novaera' cowpea plants under levels of irrigations and with or without fertilization.

\begin{tabular}{lcccc}
\hline \multirow{2}{*}{$\begin{array}{c}\text { Fontes de } \\
\text { variação }\end{array}$} & GL & PROD & NVP & M100G \\
\cline { 3 - 5 } & 2 & 18771,31 & 0,25 & 7,99 \\
Blocos & 3 & $487458,42^{*}$ & 11,70 & 7,84 \\
Irrigação (I) & 1 & $2354261,76^{*}$ & $85,88^{*}$ & $74,54^{*}$ \\
Adubação (A) & 3 & 333112,46 & 22,84 & 9,62 \\
I x A & 14 & 106245,17 & 4,78 & 9,80 \\
Resíduo & & 42,06 & 39,74 & 14,47 \\
\hline C.V. (\%) & & &
\end{tabular}

Nota: *Significativo pelo teste " $\mathrm{F}$ " a $5 \%$ de probabilidade. Note: *Significant by the " $F$ " test at $5 \%$ probability. Fonte: Autoria própria. Own authorship.

Segundo Schlichting et al. (2015), os índices indiretos de clorofila, como o índice de clorofila Falker, apresentam alta correlação com a concentração de nitrogênio na planta, todavia, no presente estudo, não foi evidenciado diferença significativa de índice de clorofila Falker entre as plantas adubadas com NPK e não adubadas, diferindo assim de outros 
trabalhos. Entretanto, vale salientar, que os trabalhos com esse tipo de comparação avaliam a adubação exclusivamente nitrogenada, diferindo deste estudo, que além da adubação nitrogenada, foi utilizado também adubação fosfatada e potássica, assim, essa complementação de diferentes adubos pode explicar estes resultados conflitantes.

Após a colheita, foram realizadas avaliações relacionadas a produção das plantas. As características número de vagens por planta e massa de 100 grãos apresentaram diferença significativa apenas para adubação e considerando a característica produtividade de grãos, foi demonstrado diferença para ambos tratamentos, tanto para irrigação, como também para adubação (Tabela 3).

Pela análise de regressão de produtividade de grãos pelos níveis de irrigações para capacidade de vaso, observa-se um efeito quadrático. Começando com produtividade média de $515,93 \mathrm{~kg} \mathrm{ha}^{-1}$ com $40 \%$ de irrigação para capacidade de vaso, chegando a máxima produtividade $\left(1.025,63 \mathrm{~kg} \mathrm{ha}^{-1}\right)$ com $72 \%$, considerado o ponto ótimo, e em seguida sofrendo um decréscimo, atingindo $636,4 \mathrm{~kg} \mathrm{ha}^{-1}$ com a máxima irrigação, ou seja, $100 \%$ de irrigação para capacidade de vaso. Assim, observa-se que para a cultivar 'BRS Novaera', irrigações acima desse ponto máximo de $72 \%$ de capacidade de vaso não foram eficientes para condução da cultura, além de gastos com água, ocasionou redução de produtividade (Figura 3).

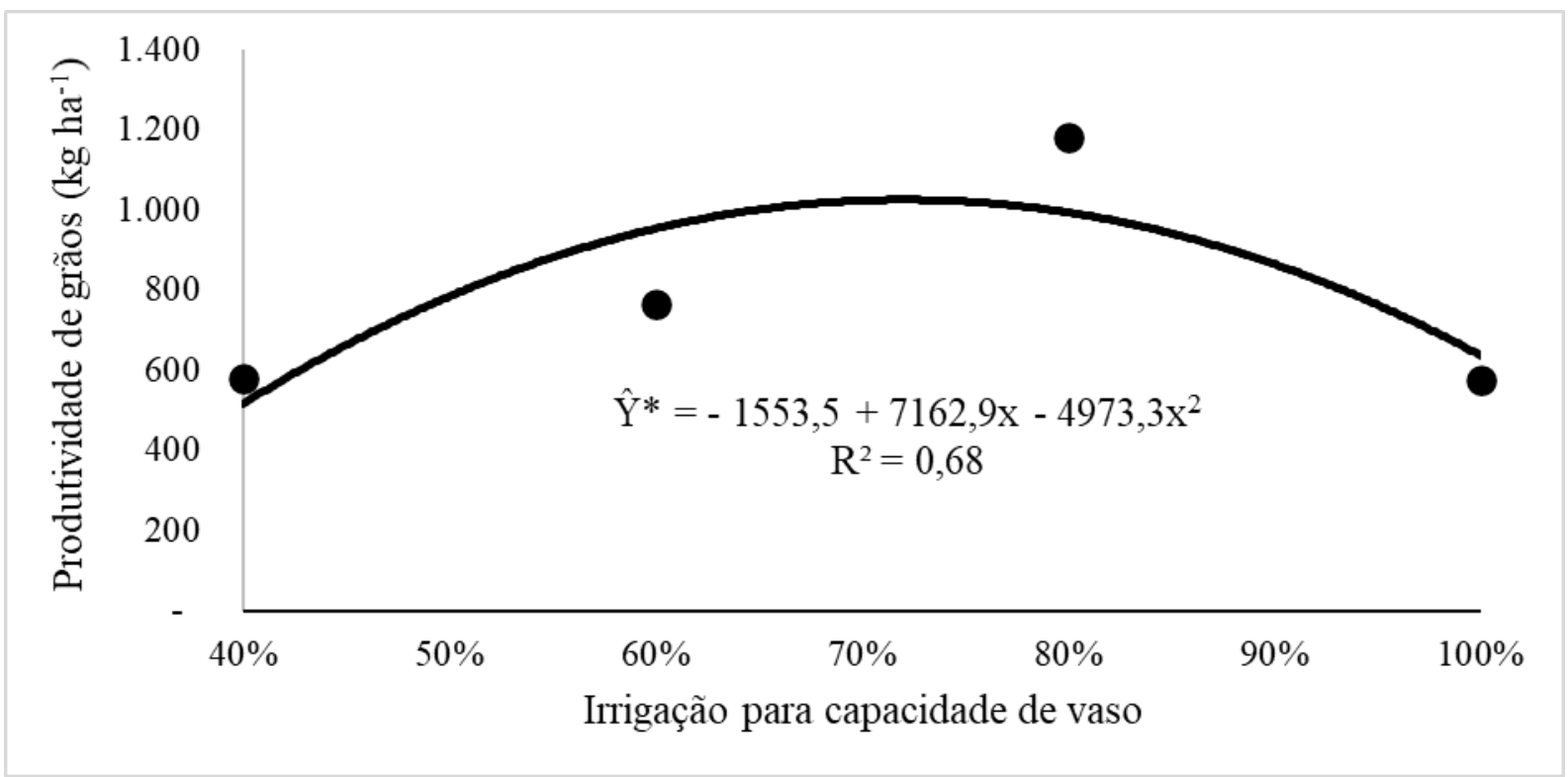

Nota: *Significativo, a 5\% de probabilidade, pela análise de variância da Regressão. Note: *Significant, at 5\% probability, by Regression analysis of variance.

Figura 3. Produtividade de grãos da cultivar de feijão-caupi 'BRS Novaera' submetida a níveis de irrigação para capacidade de vaso. Grain yield of 'BRS Novaera' cowpea cultivar submitted to irrigation levels for pot capacity.

Fonte: Autoria própria. Own authorship.

Comportamento quadrático com relação a produtividade de grãos também foram relatados por Tagliaferre et al. (2013), que estudando lâminas de irrigação (240 mm até 578 $\mathrm{mm}$ ) para produtividade de grãos de feijão-caupi na mesma região do estudo, observaram máxima produtividade $\left(2.820,03 \mathrm{~kg} \mathrm{ha}^{-1}\right)$ obtida com a lâmina de irrigação de 462,21 mm e Andrade Júnior et al. (2002), que constataram em experimento no Piauí, que a cultivar BR 14 
Mulato após um ponto ótimo de irrigação $(389,9 \mathrm{~mm})$, ocasionou um decréscimo em sua produtividade de grãos.

Para Tagliaferre et al. (2013) estes resultados comprovam que o excesso de água no solo, da mesma forma que o déficit, também prejudica a produção de grãos. Segundo Boyer (1978), a planta de feijão-caupi é classificada como moderadamente tolerante, tanto à deficiência hídrica quanto ao excesso de água no solo.

Corroboram com estas conclusões o estudo de Mousa e Qurashi (2018), que analisando características de três cultivares de feijão-caupi sob déficit hídrico em diferentes estádios de crescimento, observaram que o tratamento submetido a irrigação plena em todo ciclo (sem déficit hídrico), também não foi o que apresentou as maiores produtividades. Os autores concluíram que uma boa produtividade de grãos secos de feijão-caupi pode ser obtida sob déficit hídrico no estádio vegetativo por 20 dias e 10 minutos de irrigação/dia.

Os resultados sugerem que dependendo da cultivar e das condições edafoclimáticas, o produtor que utiliza irrigação poderá economizar com os custos deste manejo, irrigando menos do que acha necessário. O produtor poderá também utilizar como auxílio econômico, estratégias para manejo racional da irrigação, que leva em consideração o preço do produto e o custo da água, conforme relatado por Calheiros et al. (1996).

Considerando a adubação, observa-se na Tabela 4, que as plantas que foram submetidas a adubação NPK apresentaram incremento em produtividade de grãos, número de vagens por planta e massa de 100 grãos.

Tabela 4. Médias de produtividade de grãos, número de vagens por planta e massa de 100 grãos em plantas da cultivar de feijão-caupi 'BRS Novaera' com ou sem adubação NPK. Average of grain yield, number of pods per plant and mass of 100 grains in plants of 'BRS Novaera' cowpea cultivar with or without NPK fertilization.

\begin{tabular}{lccc}
\hline Adubação & $\begin{array}{c}\text { Produtividade de grãos } \\
\left(\mathrm{kg} \mathrm{ha}^{-1}\right)\end{array}$ & $\begin{array}{c}\text { Número de vagens } \\
\text { por planta }\end{array}$ & Massa de 100 grãos (g) \\
\hline Com NPK & $1.088,13 \mathrm{a}$ & $7,4 \mathrm{a}$ & $23,40 \mathrm{a}$ \\
Sem NPK & $461,73 \mathrm{~b}$ & $3,6 \mathrm{~b}$ & $19,88 \mathrm{~b}$ \\
\hline
\end{tabular}

Nota: *Médias seguidas pela mesma letra na coluna não diferem entre si, pelo teste Tukey a $5 \%$ de probabilidade. Note: *Means followed by the same letter in the column do not differ from each other, by the Tukey test at $5 \%$ probability.

Fonte: Autoria própria. Own authorship.

Houve aumento na produtividade de grãos quando adicionado a adubação NPK. Sem adubação a média foi de apenas $461,73 \mathrm{~kg} \mathrm{ha}^{-1}$ e com adubação ocorreu um aumento de 626,4 $\mathrm{kg} \mathrm{ha}{ }^{-1}$, ou 135,7\%, chegando a $1.088,13 \mathrm{~kg} \mathrm{ha}^{-1}$, que demonstra a importância de uma adubação a base de NPK, principalmente em solos pobres, que geralmente são encontrados na região de estudo.

Corroborando com estes resultados, porém estudando apenas o efeito do nitrogênio, Tagliaferre et al. (2013) analisando níveis de $\mathrm{N}$ em campo, no mesmo local do presente estudo, observaram que a adubação nitrogenada proporcionou acréscimos na produtividade de grãos de feijão-caupi, chegando a $2.525 \mathrm{~kg} \mathrm{ha}^{-1}$, quando aplicado o valor máximo de $\mathrm{N}$ (90 kg $\mathrm{ha}^{-1}$ ), porém com uma resposta menor a adubação, visto que sem aplicação de $\mathrm{N}$ também 
apresentou um valor satisfatório, com $1.904 \mathrm{~kg} \mathrm{ha}^{-1}$. Farineli e Lemos (2010) testando doses de $\mathrm{N}$ na cultura do feijão-caupi também constataram efeito linear e positivo para produção de grãos com o acréscimo da adubação de nitrogênio.

O número de vagens por planta foi outra característica que apresentou crescimento no tratamento com NPK, comparando com o tratamento sem NPK. Nas plantas com adução NPK, a média foi de 7,4 vagens por planta, 105,5\% a mais que os observados nas plantas sem uso de NPK, que apresentaram média de apenas 3,6 vagens por planta.

Considerando apenas o nutriente fósforo, um aumento de número de vagens por planta também foi observado por Bezerra et al. (2018), que estudando características de feijão-caupi submetidas a diferentes níveis de $\mathrm{P}$, observaram um aumento de $168,4 \%$ no número de vagens por planta, comparando o tratamento com a máxima aplicação de $\mathrm{P}_{2} \mathrm{O}_{5}\left(240 \mathrm{~kg} \mathrm{ha}^{-1}\right)$, com o tratamento controle (sem aplicação de $\mathrm{P}_{2} \mathrm{O}_{5}$ ). Segundo os autores, o número de vagens por planta é o principal componente de produção do feijão-caupi. Indicando assim a importância desta característica e o efeito crescente dela quando submetida a adubação.

Para massa de 100 grãos, conforme analisado na Tabela 3, essa característica apresentou significância apenas para adubações, o nível de irrigação não influenciou na massa de 100 grãos. Estes resultados diferiram aos observados por Oliveira et al. (2011), que trabalhando com a mesma cultivar, constataram interação significativa entre lâminas de água e doses de fósforo.

A massa de 100 grãos apresentou aumento de 17,7\% com adubação NPK, chegando a 23,4 g, sem NPK sua massa foi 19,88 g (Tabela 4). O aumento foi proporcionalmente igual aos observados por Pereira Júnior et al. (2015), que avaliando a adubação nitrogenada e fosfatada na cultura de feijão-caupi irrigado, utilizando a cultivar 'Costela de vaca', observaram que as doses de fertilizantes que resultaram em maior massa de 100 grãos foi com $75 \mathrm{~kg} \mathrm{ha}^{-1}$ de $\mathrm{N}+25 \mathrm{~kg} \mathrm{ha}^{-1}$ de $\mathrm{P}_{2} \mathrm{O}_{5}$, que resultaram em massa de 100 grãos de 29,7 g, equivalente a $18,5 \%$ maior que o tratamento testemunha, sem aplicação de nitrogênio e fosforo, que apresentou $24,2 \mathrm{~g}$. Os resultados sugerem que a adubação faz com que as plantas absorvam mais nutrientes e que consequentemente potencializem suas reações fisiológicas, gerando grãos em maiores quantidade e com maiores massas, fatores que são vantajosos para os produtores.

Na Tabela 5, observa-se que as características número de grãos por vagem, massa de vagem, índice de grãos e comprimento de vagem não apresentaram diferença significativa para nenhum dos tratamentos submetidos.

As características número de grãos por vagem, que apresentou média de 3,96, massa de vagem, média de $1,2 \mathrm{~g}$, índice de grãos, média de 76,2\% e comprimento de vagem, que apresentou média de 9,6 cm, não foram afetadas pelos diferentes níveis de irrigação e também não apresentaram variações com adubação NPK, indicando que estas características não sofrem interferências pela irrigação e/ou adubação.

Oliveira et al. (2011) avaliando diferentes lâminas de irrigação e doses de adubo fosfatado em Roraima, utilizando a mesma cultivar 'BRS Novaera', também não observaram influência da irrigação sobre número de grãos por vagem e comprimento de vagem, todavia, 
ambas características foram afetadas pela adubação fosfatada, apresentando efeito linear, diferindo deste estudo.

Tabela 5. Resumo da análise de variância e coeficientes de variação referentes às características número de grãos por vagem (NGV), massa de vagem (MV), índice de grãos (IG) e comprimento de vagem (COMV) da cultivar de feijão-caupi 'BRS Novaera' submetida a diferentes níveis de irrigação e com ou sem adubação. Summary of the analysis of variance and coefficients of variation referring to the number of grains per pod (NGV), pod mass $(P V)$, grain index (IG) and pod length (COMV) of cowpea 'BRS Novaera' submitted to different levels of irrigation and with or without fertilization.

\begin{tabular}{lccccc}
\hline Fontes de & & \multicolumn{4}{c}{ Quadrados médios } \\
\cline { 3 - 6 } variação & GL & NGV & MV & \multicolumn{1}{c}{ IG } & COMV \\
\hline Blocos & 2 & 0,46 & 0,09 & 18,16 & 0,04 \\
Irrigação (I) & 3 & 0,81 & 0,07 & 29,20 & 0,64 \\
Adubação (A) & 1 & 0,12 & 0,12 & 2,98 & 0,42 \\
I x A & 3 & 1,50 & 0,05 & 25,85 & 0,50 \\
Resíduo & 14 & 0,74 & 0,08 & 39,10 & 1,07 \\
\hline C.V. (\%) & & 21,75 & 26,07 & 8,20 & 10,79 \\
\hline
\end{tabular}

Nota: *Significativo pelo teste "F" a $5 \%$ de probabilidade. Note: *Significant by the " $F$ " test at $5 \%$ probability. Fonte: Autoria própria. Own authorship.

Os resultados para as características comprimento de vagem e massa de 100 grãos foram similares aos observados por Bezerra et al. (2003), que analisaram a cultivar Epace-11 e Ferreira (1992), que estudou as cultivares Br 1, Mimoso, Epace 1 e Pitiúba. Esses autores também constataram que o déficit hídrico não influenciou essas duas varáveis. Apesar de não apresentar diferença para estas características, a adubação NPK aumentou atributos importantes para o feijão-caupi, como produtividade de grãos e número de vagens por planta e deve ser levada em consideração em cultivos desta cultura para melhoria financeira e social, visto que é utilizada por muitos agricultores com vulnerabilidade social.

\section{CONCLUSÕES}

Pelas condições observadas neste trabalho, conclui-se que a maior produtividade de grãos foi adquirida com $72 \%$ de irrigação para capacidade de vaso. A adubação NPK resultou em incremento significativo no número de vagens por planta e produtividade de grãos para a cultivar 'BRS Novaera'.

\section{AGRADECIMENTOS}

À Coordenação de Aperfeiçoamento de Pessoal de Nível Superior (CAPES), à Fundação de Amparo à Pesquisa do Estado da Bahia (FAPESB) e à Universidade Estadual do Sudoeste da Bahia (UESB). 


\section{REFERÊNCIAS BIBLIOGRÁFICAS}

ANDRADE JUNIOR, A.S.; RODRIGUES B.H.N.; FRIZZONE, J.A.; CARDOSO, M.J.; BASTOS, E.A.; MELO F. de B. Níveis de irrigação na cultura do feijão caupi. Revista Brasileira de Engenharia Agrícola e Ambiental, Campina Grande, v. 6, n. 1, p.17-20, 2002. Disponível em: http://www.scielo.br/pdf/rbeaa/v6n1/v6n1a04.pdf. Acesso em: 14 fev. 2019.

BASTOS, E. A.; ANDRADE JÚNIOR, A. S.; CARDOSO, M. J. Manejo da irrigação. In: do VALE, J. C.; BERTINI, C.; BORÉM, A. (Ed.) Feijão-caupi: do plantio à colheita. Viçosa, MG: UFV, 2017. cap. 10, p. 224-243.

BASTOS, E. A.; NASCIMENTO, S. P.; SILVA, E. M.; FREIRE FILHO, F. R.; GOMIDE, R. L. Identification of cowpea genotypes for drought tolerance. Revista Ciência Agronômica, Fortaleza, v. 42, n. 1, p.100-107, 2011. Disponível em: http://www.scielo.br/pdf/rca/v42n1/v42n1a13.pdf. Acesso em: 30 jan. 2019.

BEZERRA, A. A. C.; COSTA FILHO, R. S.; OLIVEIRA, S. R. M.; FREIRE FILHO, F. R. Morphophysiological biometry and grain production in cowpea under different phosphorus levels. Comunicata Scientiae, Teresina, v. 9, n. 2, p.275-281, 2018. Disponível em: https://www.comunicatascientiae.com.br/comunicata/article/view/2398/556. Acesso em: 03 fev. 2019.

BEZERRA, F. M. L.; ARARIPE, M. A. E.; TEÓFILO, E. M.; CORDEIRO, L. G.; SANTOS, J. J. A. Feijão-caupi e déficit hídrico em suas fases fenológicas. Revista Ciência Agronômica, Fortaleza, v. 34, n. 1, p.5-10, 2003.

BOYER, J. S. Water deficits and photosynthesis. In: KOZLOWSKI, T. T. (ed.) Water deficits and plant growth. New York: Academic, 1978. v. 4, p. 154-191.

CAlHEIROS, C. B. M.; QUEIROZ, J. E.; FRIZZONE, J. A.; PESSOA, P. C. S. Estratégias ótimas de irrigação do feijoeiro: água como fator limitante da produção. Pesquisa Agropecuária Brasileira, Brasília, v. 31, n. 7, p.509-515, 1996. Disponível em: http://seer.sct.embrapa.br/index.php/pab/article/view/4512/1798. Acesso em: 16 jan. 2020.

CASAROLI, D.; JONG VAN LIER, Q. Critérios para determinação da capacidade de vaso. Revista Brasileira de Ciências do Solo, Viçosa, v. 32, n. 1, p.59-66, 2008. Disponível em: http://www.scielo.br/pdf/rbcs/v32n1/07.pdf. Acesso em: 10 out. 2018.

CRUZ, C. S. A.; PEREIRA, E. R. L.; SILVA, L. M. M.; MEDEIROS, M. B.; GOMES, J. P. Repelência do Callosobruchus maculatus (COLEOPTERA: BRUCHIDAE) sobre grãos de feijão caupi tratado com óleos vegetais. Revista Verde de Agroecologia e Desenvolvimento Sustentável, Pombal, v. 7, n. 3, p.01-05, 2012. Disponível em: https://www.gvaa.com.br/revista/index.php/RVADS/article/view/1256/1180. Acesso em: 05 jan. 2019.

DASTAGER, S. G.; DEEPA, C. K.; PANDEY, A. Plant growth promoting potential of Pontibacter niistensis in cowpea (Vigna unguiculata (L.) Walp.). Applied Soil Ecology, Amsterdam, v. 49, p.250-255, 2011. 
FARINELLI, R.; LEMOS, L. B. Produtividade, eficiência agronômica, características nutricionais e tecnológicas do feijão adubado com nitrogênio em plantio direto e convencional. Bragantia, Campinas, v. 69, n. 1, p.165-172, 2010. Disponível em: http://www.scielo.br/pdf/brag/v69n1/21.pdf. Acesso em: 17 jan. 2019.

FERREIRA, D. F. Sisvar: a Guide for its Bootstrap procedures in multiple comparisons. Ciência e Agroecnologia, Lavras, v. 38, n. 2, p.109-112, 2014. Disponível em: http://www.scielo.br/pdf/cagro/v38n2/a01v38n2.pdf. Acesso em: 13 jan. 2019.

FERREIRA, L. G. R. Avaliação das respostas fisiológicas e produtividade biológica de cultivares de caupi (Vigna ungüiculada (L) Walp) sob diferentes regimes hídricos. 1992. 11 f. Tese (Concurso Professor Titular) - Universidade Federal do Ceará, Fortaleza, 1972.

FREIRE FILHO, F. R.; CRAVO, M. S.; VILARINHO, A. A.; CAVALCANTE, E. S.; FERNANDES, J. B.; SAGRILO, E.; RIBEIRO, V. Q.; ROCHA, M. M.; SOUZA, F. de F.; LOPES, A de M.; GONÇALVES, J. R. P.; CARVAlHO, H. L.; RAPOSO, J. A. A.; SAMPAIO, L. S. BRS Novaera: Cultivar de Feijão Caupi de Porte Semi-Ereto. Belém: Embrapa, 2008. 4 p. (Comunicado técnico, 215). Disponível em: https://ainfo.cnptia.embrapa.br/digital/bitstream/item/27806/1/Com.Tec.215.pdf_. Acesso em: 05 jan. 2019.

INSTITUTO BRASILEIRO DE GEOGRAFIA E ESTATÍSTICA - IBGE Sistema IBGE de Recuperação Automática - SIDRA. 2020. Disponível em: https://sidra.ibge.gov.br. Acesso em: 18 mar. 2020.

MARTINS, C. M.; MARTINS, S. C. S.; BORGES, W. L. Correção da acidez, adubação e fixação biológica. In: do VALE, J. C.; BERTINI, C.; BORÉM, A. (Ed.) Feijão-caupi: do plantio à colheita. Viçosa: UFV, 2017. cap. 5, p. 89-112.

MELO, F. B.; CARDOSO, M. J. Solos e adubação. Cultivo de feijão-caupi. Brasília, DF: Embrapa Meio-Norte, 2003. (Sistema de Produção, 2). Disponível em: https://www.spo.cnptia.embrapa.br/temas-publicados. Acesso em: 28 fev. 2019.

MIRANDA, R. S.; SUDÉRIO, F. B.; MARQUES, E. C., GOMES-FILHO, E. Accumulation and partition of $\mathrm{Fe}, \mathrm{Zn}, \mathrm{Cu}, \mathrm{Mn}$ and $\mathrm{Na}$ in macro and micronutrient-deficient cowpea plants. Journal of Advances in Agriculture, Punjab, v. 7, n. 2, p.1036-1043, 2017.

MONTEIRO, F. P. R.; CHAGAS JUNIOR, A. F.; REIS, M. R.; SANTOS, G. R.; CHAGAS, L. F. B. Efeitos de herbicidas na biomassa e nodulação do feijão-caupi inoculado com rizóbio. Revista Caatinga, Mossoró, v. 25, n. 3, p.44-51, 2012. Disponível em: https://periodicos.ufersa.edu.br/index.php/caatinga/article/view/2550/pdf_8. Acesso em: 22 jan. 2019.

MOUSA, M. A.; AL QURASHI, D. Growth and yield of cowpea (Vigna unguiculata L.) cultivars under water deficit at different growth stages. Legume Research, Karnal, v. 41, n. 5, p.702-709, 2018.

OLIVEIRA, A. E. S.; SIMEÃO, M.; MOUSINHO, F. E. P.; GOMES, R. L. F. Desenvolvimento do feijão-fava (Phaseolus lunatus L.) sob déficit hídrico cultivado em ambiente protegido. Holos, Natal, v. 1, p.143-151, 2014. Disponível em: 
http://www2.ifrn.edu.br/ojs/index.php/HOLOS/article/view/1867/784. Acesso em: 15 jan. 2020.

OLIVEIRA, G. A.; ARAÚJO, W. F.; CRUZ, P. L. S.; LIMA, W. L. M.; FERREIRA, G. B. Resposta do feijão-caupi as lâminas de irrigação e as doses de fósforo no cerrado de Roraima. Revista Ciência Agronômica, Fortaleza, v. 42, n. 4, p.872-882, 2011. Disponível em: http://www.scielo.br/pdf/rca/v42n4/a08v42n4.pdf. Acesso em: 12 jan. 2019.

PEREIRA JUNIOR, E. B.; OLIVEIRA, F. H. T.; OLIVEIRA, F. T.; SILVA, G. F.; HAFLE, O. M.; SILVA, A. R. C. Adubação nitrogenada e fosfatada na cultura do feijão caupi irrigado no município de Sousa - PB. Global Science and Technology, Rio Verde, v. 8, n. 1, p.110121, 2015.2 Disponível em: https://rv.ifgoiano.edu.br/periodicos/index.php/gst/article/view/689/450. Acesso em: 22 fev. 2019.

RIVAS, R.; FALCÃO, H. M.; RIBEIRO, R. V.; MACHADO, E. C.; PIMENTEL, C.; SANTOS, M. G. Drought tolerance in cowpea species is driven by less sensitivity of leaf gas exchange to water deficit and rapid recovery of photosynthesis after rehydration. South African Journal of Botany, Pietermaritzburg, v. 103, p.101-107, 2016.

RODRIGUES, A. C.; ANTUNES, J. E.; MEDEIROS, V. V.; BARROS, B. G. F.; FIGUEIREDO, M. V. B. Resposta da co-inoculação de bactérias promotoras de crescimento em plantas e Bradyrhizobium sp. em caupi. Bioscience Journal, Uberlândia, v. 28, s. 1, p.196-202, 2012. Disponível em: http://www.seer.ufu.br/index.php/biosciencejournal/article/view/13174/8364. Acesso em: 23 fev. 2019.

SALLA, L.; RODRIGUES, J. C.; MARENCO, R. A. Teores de clorofila em árvores tropicais determinados com o SPAD-502. Revista Brasileira de Biociências, Porto Alegre, v. 5, s. 2, p.59-161, 2007. Disponível em: http://www.ufrgs.br/seerbio/ojs/index.php/rbb/article/view/174/163. Acesso em: 10 dez. 2019.

SANTIAGO, F. L A.; SANTIAGO, F. E. M.; LUSTOSA FILHO, J. F.; RATKE, R. F. Plant growth and symptomatology of macronutrient deficiencies in cowpea plants. Comunicata Scientiae, Bom Jesus, v. 9, n. 3, p.503-508, 2018.

SANTOS, J. F.. Produtividade de cultivares de feijão-caupi no Agreste Paraibano. Tecnologia e Ciência Agropecuária, João Pessoa, v. 7, n. 4, p.31-36, 2013. Disponível em: http://revistatca.pb.gov.br/edicoes/volume-07-2013/volume-7-numero-4-dezembro2013/tca7406.pdf. Acesso em: 06 jan. 2019.

SCHLICHTING, A. F.; BONFIM-SILVA, E. M.; SILVA, M. D. C.; PIETRO-SOUZA, W.; da SILVA, T. J.; FARIAS, L. D. N. Efficiency of portable chlorophyll meters in assessing the nutritional status of wheat plants. Revista Brasileira de Engenharia Agrícola e Ambiental, Campina Grande, v. 19, n. 12, p.1148-1151, 2015. Disponível em: http://www.scielo.br/pdf/rbeaa/v19n12/1415-4366-rbeaa-19-12-1148.pdf. Acesso em: 18 jan. 2019. 
TAGLIAFERRE, C.; SANTOS, T. J.; SANTOS, L. C.; SANTOS NETO, I. J.; ROCHA, F. A.; PAULA, A. Características agronômicas do feijão caupi inoculado em função de lâminas de irrigação e de níveis de nitrogênio. Revista Ceres, Viçosa, v. 60, n. 2, p.242-248, 2013. Disponível em: http://www.scielo.br/pdf/rceres/v60n2/v60n2a13.pdf. Acesso: 05 jan. 2019.

TAIZ, L.; ZEIGER, E.; MØLLER, I. M.; MURPHY, A. Fisiologia e desenvolvimento vegetal. 6. ed. Porto Alegre: Artmed, 2017. 858 p.

YADAV, S. S.; HUNTER, D.; REDDEN, B.; NANG, M.; YADAVA, D. K.; HABIBI, A. B. Impact of climate change on agriculture production, food, and nutritional security. In: REDDEN, R. YADAV, S. S.; MAXTED, N.; DULLOO, M. S.; GUARINO, L.; SMITH, P. (ed.) Crop wild relatives and climate change. New Jersey, USA: Wiley; 2015. p. 1-23. 